\title{
Characteristics of movable fluids in tight sandstone reservoir and its influencing factors: a case study of Chang 7 reservoir in the Southwestern of Ordos Basin
}

\author{
Yongqiang $\mathrm{Xu}^{1,2,3} \cdot$ Linyu Liu ${ }^{1,2} \cdot$ Yushuang $\mathrm{Zhu}^{1,2}$
}

Received: 19 March 2021 / Accepted: 26 July 2021 / Published online: 5 August 2021

(c) The Author(s) 2021

\begin{abstract}
Aiming at the problem of complicated occurrence and flow state of the fluid in tight sandstone reservoir, this paper takes Chang 7 reservoirs in Southwestern of Ordos Basin as an example to analyze the occurrence characteristics of movable fluids by nuclear magnetic resonance experiment, while takes a series of microscopic experiments to analyze the influencing factors of difference of movable fluids. The results show that the $T_{2}$ spectrum curves of fluid-saturated samples from Chang 7 reservoirs in the study area are dominated by the unimodal shape and the left-high-peak-right-low-peak bimodal shape. After centrifugation, the $T_{2}$ spectrum curves are dominated by the left-high-peak-right-low-peak bimodal shape. The average movable fluid saturation is $33.27 \%$, and the average $T_{2}$ cutoff value is $13.61 \mathrm{~ms}$. The movable fluids are mainly distributed in medium and large pores, and a small amount is distributed in small pores. The occurrence characteristics of movable fluids in tight reservoirs are complex and not controlled by a single factor. The size of throats and the connectivity of pore-throat have obvious effects on the saturation of movable fluids. The small size of throats and poor connectivity of pore-throat in tight reservoirs not only restrict the fluids in micropores, but also make the fluids in macropores difficult to flow under the control of small throats. The development of clay minerals will make the pore throats smaller, more complex and have poorer connectivity, and increase the fluid seepage resistance. On the other hand, it will make the specific surface area larger, which will cause a large number of fluids adsorbed on the clay surface and difficult to flow, resulting in the reduction of movable fluid saturation.
\end{abstract}

Keywords Tight sandstone reservoirs $\cdot$ NMR $\cdot$ Movable fluid $\cdot$ Pore throat structure $\cdot$ Clay minerals $\cdot$ Influencing factors

\section{Introduction}

In the global unconventional petroleum exploration field, the resources contained in tight sandstone reservoirs (tight oil and gas) are becoming the focus and hot spot of exploration (Zou et al. 2014). In recent years, many scholars have done a lot of work on the microscopic pore-throat characteristics

Yushuang Zhu

yshzhu@nwu.edu.cn

1 State Key Laboratory of Continental Dynamics, Northwest University, Xi' an 710069, China

2 Department of Geology, Northwest University, Xi'an 710069, China

3 Research Institution of Petroleum Exploration and Development, PetroChina Tarim Oilfield Company, Korla 841000, Xinjiang, China and seepage characteristics of tight reservoirs through various testing methods. They believed that a large number of micro-nano-scale pore throats are developed in tight sandstone reservoirs (Zou et al. 2011; Bai et al. 2014). The pore throats are small and their structures are complex, resulting in poor connectivity between pores and throats with difficulty in fluid seepage (Yao et al. 2013; Yang et al. 2017). Movable fluid parameters can effectively reflect the fluidity of fluid in the reservoir, which is a comprehensive characterization of the quality of the reservoir and can be used as an important indicator for the evaluation of the development potential of tight oil. The study of the occurrence and distribution characteristics of the movable fluids and the analysis of its influencing factors can provide a scientific basis for the effective evaluation and rational development of tight reservoirs (Shi et al. 2016).

Nuclear magnetic resonance (NMR) technology has the advantages of fast, non-destructive, repeatable, etc. It is an 
important means of reservoir evaluation and has been widely used in the field of unconventional oil and gas reservoirs (Guo et al. 2018). The NMR experiments could extract the characteristic variables reflecting the pore structure of the rock specimens, which is used to quantitatively characterize the pore structure, from the $T_{2}$ spectrum (Fang et al. 2017). At present, the application of nuclear magnetic resonance logging has been widely used to evaluate the pore structure of reservoirs ( $\mathrm{Li}$ et al. 2010; Liang et al. 2015; Baouche et al. 2017). Some scholars believe that the value of the transverse relaxation time $\left(T_{2}\right)$ in the NMR $T_{2}$ spectrum of a fluidsaturated sample is proportional to the pore throat radius $(r)$. By analyzing the relationship between $T_{2}$ and $\mathrm{r}$ by various methods, the NMR $T_{2}$ spectrum can be converted into a pore throat radius distribution (Daigle et al. 2015; Liu et al. 2018; Chen et al. 2019). Some scholars use the NMR $T_{2}$ spectrum distribution to obtain the permeability of tight sandstone reservoirs and establish permeability prediction models (Pape et al. 2009; Xiao et al. 2014; Lala et al. 2015; Li et al. 2016).

In the field of fluid seepage, NMR may become an alternative method to evaluate rock wettability (Zhang et al. 2000; Guana et al. 2002; Al-Mahrooqi et al. 2003, 2006; Chen et al. 2006; Xiao et al. 2017). Some scholars combined NMR with oil-water displacement experiments to analyze the occurrence characteristics of reservoir fluids before and after water flooding or to analyze remaining oil (Yang et al. 2013; Li et al. 2014; Gao et al. 2015). The NMR technique can also be used to determine the irreducible water saturation in order to study the change of the irreducible water saturation of the cores of low-permeability gas reservoirs under different permeability and different gas flooding conditions (Yang et al. 2008). At present, the most widely used NMR technology is to analyze the characteristics of movable fluids in reservoirs, which has become one of the important means to study the characteristics of reservoir seepage. For example, Lai et al. (2016, 2018a, b) measured a series of parameters reflecting pore throat structure and movable fluid by NMR and other experiments and then analyzed the saturation distribution of movable fluid and its influencing factors. Gao et al. (2015) determined the movable fluid percentage and movable fluid porosity of 264 core samples of Yanchang Formation in Ordos Basin by using nuclear magnetic resonance (NMR) technology. It is considered that the movable fluid parameters are the comprehensive reflection of micro-characteristics of ultra-low permeability reservoir. Li et al. (2018a, b, c) analyzed the occurrence characteristics and main controlling factors of movable fluids in typical low-porosity and low-permeability reservoir. The main controlling factors that contribute to the obviously different occurrence characteristics of movable fluids are demonstrated to be pore type, pore-throat radius, porethroat radius ratio, sorting coefficient, effective pore-throat volume, and clay mineral filling. Jin et al. $(2020,2021)$ analyzed the nuclear magnetic resonance characterization of petrophysical properties in tight sandstone reservoirs and then proposed a method for the continuous and quantitative characterization of bound and movable fluid microdistribution in porous rocks based on nuclear magnetic resonance (NMR) measurements.

Some studies have been done on the occurrence characteristics of movable fluids in tight reservoirs, but the tight reservoirs in different regions and different layers have different characteristics in various aspects, and the predecessors did not focus on the analysis of micro pore throats, especially the effects of nanometer-size-scale pore throats on the occurrence characteristics of the movable fluids. This paper takes the Chang 7 tight reservoirs in the Southwestern Ordos Basin as the research object, analyzes the occurrence characteristics of the movable fluids by NMR experiments, and also analyzes the influencing factors of the difference of movable fluids using casting thin section (CTS), scanning electron microscope (SEM), pressure-controlled mercury intrusion (PCMI), rate-controlled mercury intrusion (RCMI), X-ray diffraction (XRD) and low-temperature nitrogen adsorption (LTNA). Moreover, it provides a theoretical basis for the evaluation and development of tight sandstone reservoirs.

\section{Geological settings}

Located in the western North China Craton, the Ordos Basin is the second-largest sedimentary basin in China and the most stable block in the North China Craton. According to its present tectonic characteristics, the Ordos Basin is subdivided into six first-order tectonic units, namely the Yimeng Uplift, Weibei Uplift, Jinxi Flexure Belt, Yishan Ramp, Tianhuan Depression, and Western Overthrust Belt. The Late Triassic Yanchang Formation in the Ordos Basin experienced three stages of formation, development, and extinction of the lake basin as a whole. The basin had a wide range and deep depression during the deposition period of the Late Triassic Chang 7, which is the peak stage of the lake basin development. The Chang $7^{3}$ period is a large-area semi-deep to deep lake sediment, which is mainly composed of thick mudstone and oil shale. It is an important source rock segment for oil and gas generation. The sand bodies of Chang $7^{2}$ and Chang $7^{1}$ are mainly composed of sandy clastic flow and turbidity flow deposits (Yang et al. 2010), interbedded vertically with mudstone (Fig. 1). In plane, the sand bodies are distributed in succession and developed on a large scale.

\section{Samples and experimental methodology}

In order to analyze the characteristics of the NMR $T_{2}$ spectrum and the influencing factors of movable fluid saturation in tight sandstone reservoirs, a large number of 


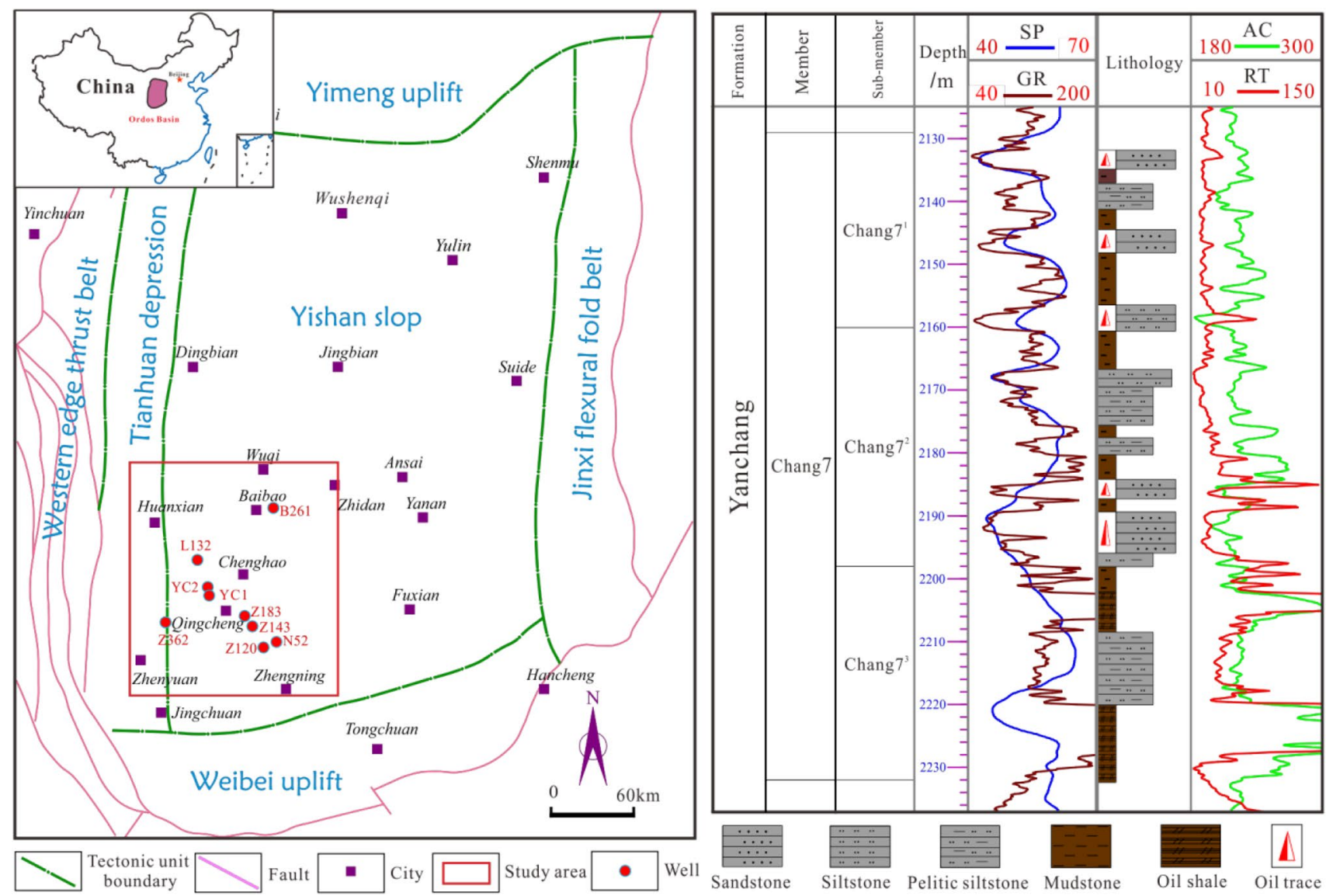

Fig. 1 Tectonic units and stratigraphic comprehensive histogram of Chang 7 member of Yanchang Formation in the Southwestern of Ordos Basin

experimental data such as physical property tests, CTS, and SEM were first collected to fully understand the basic characteristics of tight sandstone reservoirs in the study area. Then, representative samples were selected for NMR,
PCMI, RCMI, XRD, LTNA, and other tests. The experimental samples were all taken from Chang 7 tight sandstone reservoir in the Southwestern Ordos Basin (Table 1).

Table 1 Basic information of the sample and the experiments involved

\begin{tabular}{|c|c|c|c|c|c|c|c|c|c|c|c|}
\hline Sample ID & Well & Depth/m & Porosity/\% & Permeability $/ 10^{-3} \mu \mathrm{m}^{2}$ & NMR & CTS & SEM & PCMI & RCMI & XRD & LTNA \\
\hline 1\# & N52 & 1773 & 10.3 & 0.007 & $\checkmark$ & $\checkmark$ & $\checkmark$ & & $\checkmark$ & & \\
\hline 2\# & N52 & 1818.3 & 9.9 & 0.01 & $\checkmark$ & $\checkmark$ & $\checkmark$ & & $\checkmark$ & & \\
\hline 3\# & YC1 & 1980.12 & 11 & 0.383 & $\checkmark$ & $\checkmark$ & $\checkmark$ & & $\checkmark$ & & \\
\hline 4\# & YC1 & 1989.06 & 11.2 & 0.013 & $\checkmark$ & $\checkmark$ & $\checkmark$ & & $\checkmark$ & & \\
\hline $5 \#$ & YC2 & 2037.7 & 11.3 & 0.014 & $\checkmark$ & $\checkmark$ & $\checkmark$ & & $\checkmark$ & & \\
\hline 6\# & $\mathrm{YC} 2$ & 2042.2 & 11.4 & 0.018 & $\checkmark$ & $\checkmark$ & $\checkmark$ & & $\checkmark$ & & \\
\hline 7\# & Z143 & 1834.58 & 12.2 & 0.016 & $\checkmark$ & $\checkmark$ & $\checkmark$ & & $\checkmark$ & & \\
\hline $8 \#$ & Z143 & 1871.1 & 11 & 0.012 & $\checkmark$ & $\checkmark$ & $\checkmark$ & & $\checkmark$ & & \\
\hline 9\# & $\mathrm{Z} 120$ & 1733.03 & 7.81 & 0.301 & $\checkmark$ & $\checkmark$ & $\checkmark$ & $\checkmark$ & & $\checkmark$ & $\checkmark$ \\
\hline $10 \#$ & Z183 & 1838.8 & 6.1 & 0.119 & $\checkmark$ & $\checkmark$ & $\checkmark$ & $\checkmark$ & & $\checkmark$ & $\checkmark$ \\
\hline 11\# & B261 & 1952 & 5.4 & 0.069 & $\checkmark$ & $\checkmark$ & $\checkmark$ & $\checkmark$ & & $\checkmark$ & $\checkmark$ \\
\hline $12 \#$ & $\mathrm{Z} 362$ & 2307.73 & 7.5 & 0.158 & $\checkmark$ & $\checkmark$ & $\checkmark$ & $\checkmark$ & & $\checkmark$ & $\checkmark$ \\
\hline 13\# & L132 & 2218.85 & 12.3 & 0.257 & $\checkmark$ & $\checkmark$ & $\checkmark$ & $\checkmark$ & & $\checkmark$ & $\checkmark$ \\
\hline
\end{tabular}




\section{NMR}

The fluid-saturated sample is placed in a uniformly distributed static magnetic field, and a certain frequency of radio frequency field is applied. At this time, the hydrogen nucleus $\left({ }^{1} \mathrm{H}\right)$ contained in the fluid will generate nuclear magnetic resonance. After removing the radio frequency field, it will generate the signal which will decay exponentially with time and is called relaxation motion. The rate of signal decay can be described by relaxation time, which is divided into longitudinal relaxation time $\left(\mathrm{T}_{1}\right)$ and transverse relaxation time $\left(T_{2}\right)$, favored by the faster measurement, $T_{2}$ is generally preferred. The transverse relaxation time $T_{2}$ value is proportional to the pore throat size, and the strength of the relaxation signal reflects the pore volume (Kenyon 1992; Wang et al. 2001, 2005). Based on this, the incremental porosity of each data point can be calculated, and the NMR $T_{2}$ spectrum can be drawn with the transverse relaxation time $T_{2}$ as the abscissa and the incremental porosity as the ordinate. The selected core plugs with a diameter of about $2.5 \mathrm{~cm}$ and a length of about $2.5 \mathrm{~cm}$ were saturated by simulation formation water. The parameters of NMR were measured by MARAN NMR analyzer based on industry standard named SY/T6490-2014. Then use the dehydration pressure of 300psi (about $2.068 \mathrm{MPa}$ ) to carry out the centrifugation experiment and measure the NMR parameters of the samples after centrifugation. The $T_{2}$ spectrum after centrifugation reflects the volume distribution of the bound fluid. According to the change of $T_{2}$ spectrum before and after centrifugation, the parameters of the movable fluid and the distribution of the movable fluid could be analyzed.

\section{Pressure-controlled mercury intrusion}

The core plugs with a diameter of about $2.5 \mathrm{~cm}$ and a length of about $2.5 \mathrm{~cm}$ were selected, and the PCMI experiment was carried out in accordance with the national standard (GB/T 29,171-2012) using MacAutoPore IV 9505 Mercury Porosimeter. The maximum mercury intrusion pressure was $200 \mathrm{MPa}$. The parameters of PCMI for pore throat structure are mainly characterized by the Laplace formula. A series of parameters reflecting pore throat size, sortability, and connectivity can be obtained by PCMI experiment.

\section{Rate-controlled mercury intrusion}

The core plugs with a diameter of about $2.5 \mathrm{~cm}$ and a length of about $1.0 \mathrm{~cm}$ were selected, and the RCMI experiment was carried out using ASPE-730 Mercury Porosimeter. Mercury was injected into samples at a very low rate of $5 \times 10^{-5} \mathrm{~mL} / \mathrm{min}$. The structural characteristics of pore throat were analyzed according to the changes of pressure and mercury volume during Mercury injection. The maximum mercury injection pressure in the experiment was 900psi (about 6.2 MPa).

\section{X-ray diffraction}

The principle of XRD experiment is that each mineral crystal has a specific X-ray diffraction pattern, and the intensity of characteristic peaks in the pattern is positively correlated with the content of the mineral in the samples. Firstly, some fractured core samples were intercepted and ground to a particle size of less than $40 \mu \mathrm{m}$. The clay minerals with particle diameters less than $10 \mu \mathrm{m}$ and less than $2 \mu \mathrm{m}$ were, respectively, extracted by aqueous suspension separation method and centrifugal separation method. Then, a Bruker D8 Focus $\mathrm{X}$-ray diffractometer was used to determine the absolute content and relative content of clay minerals, respectively.

\section{Low-temperature nitrogen adsorption}

The basic principle of LTNA experiment is that nitrogen adsorption and capillary condensation occur in nanopores of rock samples under the low-temperature condition. Samples were ground to $5-8 \mathrm{~mm}$ particles and dried, weighed, vacuumed, and degassed. $\mathrm{N}_{2}$ adsorption desorption was performed using ASAP 2460 from Micromeritics Instrument Ltd., U.S. at liquid nitrogen temperature $\left(-195.8^{\circ} \mathrm{C}\right)$. The specific surface area was calculated by Barrett-Emmett-Teller (BET) model, and the pore volume and pore size distribution were calculated by Barrett-Joyner-Halenda (BJH) method.

\section{Results and discussion}

\section{Distribution characteristics of NMR $T_{2}$ spectrum}

The response of NMR $T_{2}$ spectrum includes two kinds of information: the size of pore throats and the volume fraction of pore throats of different sizes in the total pore space. This study combines the "three porosity component percentage method" and the "pore component calculation method" (Xiao 2008; Liu et al. 2009). The value of $T_{2}$ is divided into three intervals of $<10 \mathrm{~ms}, 10-100 \mathrm{~ms}$, and $>100 \mathrm{~ms}$. Define $S_{1}, S_{2}$, and $S_{3}$ as the percentage of envelope area and total envelope area of $T_{2}$ spectrum in three intervals of $<10 \mathrm{~ms}, 10-100 \mathrm{~ms}$, and $>100 \mathrm{~ms}$, respectively. The pore components $S_{1}, S_{2}$, and $S_{3}$ represent the proportions of small, medium, and large pores in the total pore, respectively.

Before centrifugation, the 13 samples of Chang 7 reservoir in the study area with various shapes of NMR $T_{2}$ spectrum curves can be roughly divided into four types: the left-high-peak-right-low-peak bimodal shape, the righthigh-peak-left-low-peak bimodal shape, the unimodal shape, 
and the inconspicuous bimodal shape. The bimodal shapes indicate that more pore types are developed in the samples, while the unimodal shape indicates that the pore type developed in the samples is relatively single and the pore sizes are well sorted (Fig. 2). According to statistics, it can be seen that the shapes of the $T_{2}$ spectrum curve before centrifugation are mainly unimodal shape, followed by inconspicuous bimodal shape. The pore throat size of the unimodal sample is well sorted, but the whole is inclined to the small pore throats, and the development of large pore throat is very little, resulting in low physical property. This has a greater impact on permeability. Therefore, in the analysis of micro pore throat characteristics of tight reservoirs, it is often concluded that the better the sortability, the lower permeability. The overall sorting performance of the pore throat of samples with inconspicuous bimodal spectrum is relatively good, and the pore throat distribution of these samples is often relatively wide and there is a certain amount of large pore throat developed, wherein it is easy to find samples with high porosity and permeability.

The pore components show that $S_{1}>S_{2}>S_{3}$ in the samples with the left-high-peak-right-low-peak bimodal spectrum, and the $T_{2}$ values corresponding to the main peaks are all distributed in the range of $1-10 \mathrm{~ms}$. There is no significant difference of the curve shape in different samples in the range of $T_{2}$ value less than $10 \mathrm{~ms}$, but the curve shape is different in the range of $T_{2}$ value more than $10 \mathrm{~ms}$, reflecting that the tight reservoirs mainly developed the micro pore throats and there is no significant difference of the size and distribution of these micro pore throats. Medium and macro pore throats are less developed, but the distribution and quantity of these medium and macro pore throats in different samples are different, and the development status of these medium and macro pore throats often has an important impact on the permeability. The samples with the right-highpeak-left-low-peak bimodal spectrum are rare, the medium
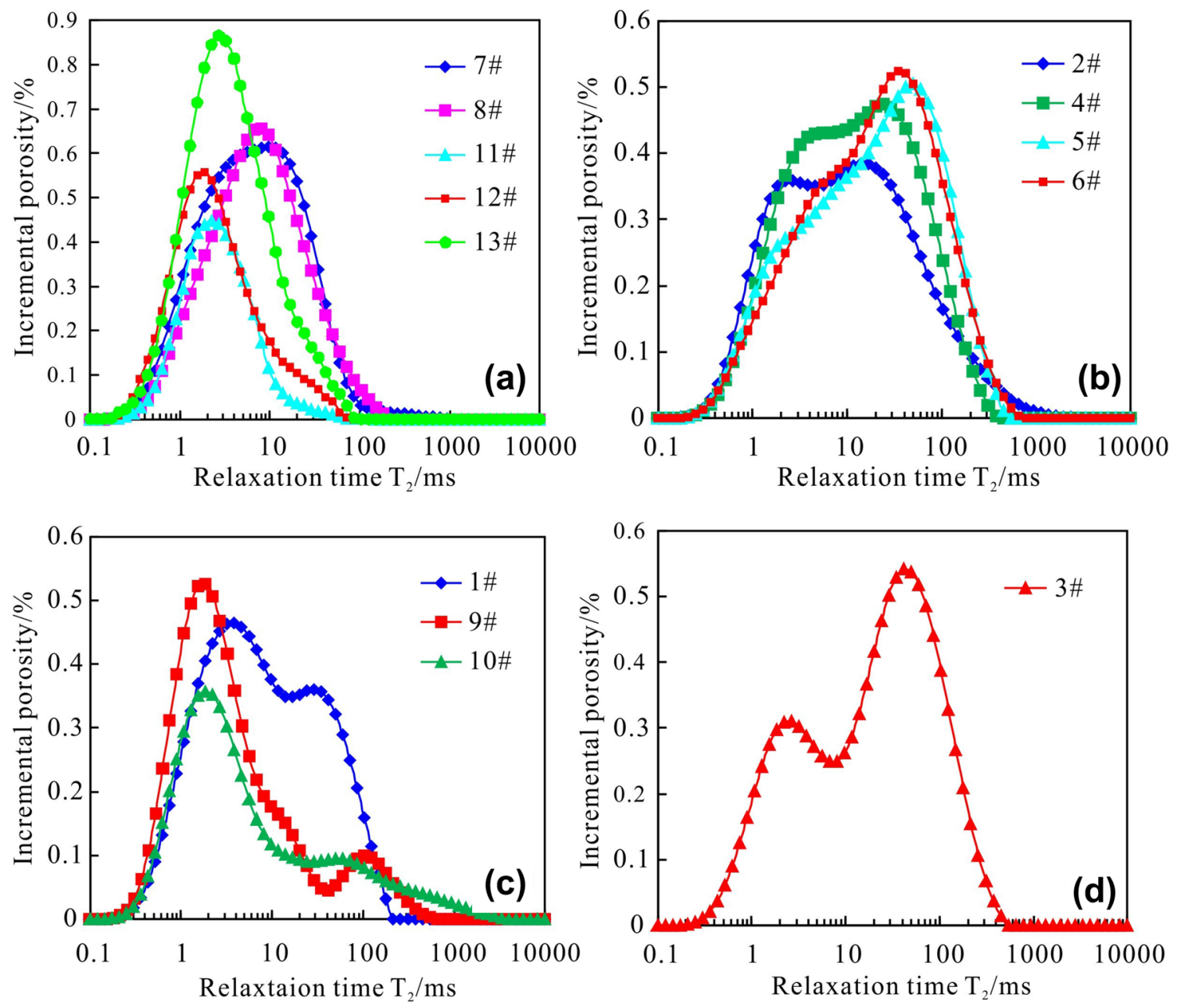

Fig. $2 T_{2}$ spectrum distribution of the samples before centrifugation: (a) the unimodal shape; (b) the inconspicuous bimodal shape; (c) the lefthigh-peak-right-low-peak bimodal shape; (d) the right-high-peak-left-low-peak bimodal shape 
and macro pore throats of these samples are well developed, and their physical properties are often relatively good.

After centrifugation, the residual fluid in the pore is called bound fluid. Therefore, the distribution of $T_{2}$ spectrum after centrifugation reflects the distribution characteristics of the bound fluid in different pores with different sizes. After centrifugation, the shapes of $T_{2}$ spectrum curve are mainly left-high-peak-right-low-peak bimodal shape, and some are unimodal shape (Fig. 3). After centrifugation, the $T_{2}$ spectrum curve is mainly distributed in the range of $T_{2}$ value less than $10 \mathrm{~ms}$, indicating that the bound fluid is mainly contained in micro pores, and secondly in medium pores. In addition, bound water can also be found in macro pores with $T_{2}$ value greater than $100 \mathrm{~ms}$ in some samples, which is due to the small throat radius, large pore-to-throat ratio and poor connectivity between pores and throats of tight reservoirs making some fluids in macro pores controlled by smaller throats and become bound fluids.

\section{$T_{2}$ cutoff value}

When the pore throat radius is reduced to a certain value, the fluid will be bound by capillary force and cannot flow. This value is called the lower limit of the pore throat radius of movable fluid, and the corresponding $T_{2}$ value on the $T_{2}$ spectrum is the $T_{2}$ cutoff value. In the analysis of NMR logging data, the empirical value method is often used to determine the $T_{2}$ cutoff value according to the reservoir development characteristics in the study area. For example, the $T_{2}$ cutoff value for tight reservoirs is empirically set as $13.895 \mathrm{~ms}$ (Ren et al. 2015; Li et al. 2018a, b, c) and is used for determining the movable fluid saturation. In indoor NMR experiments, the $T_{2}$ cutoff value is determined according to the change of $T_{2}$ spectrum before and after centrifugation.

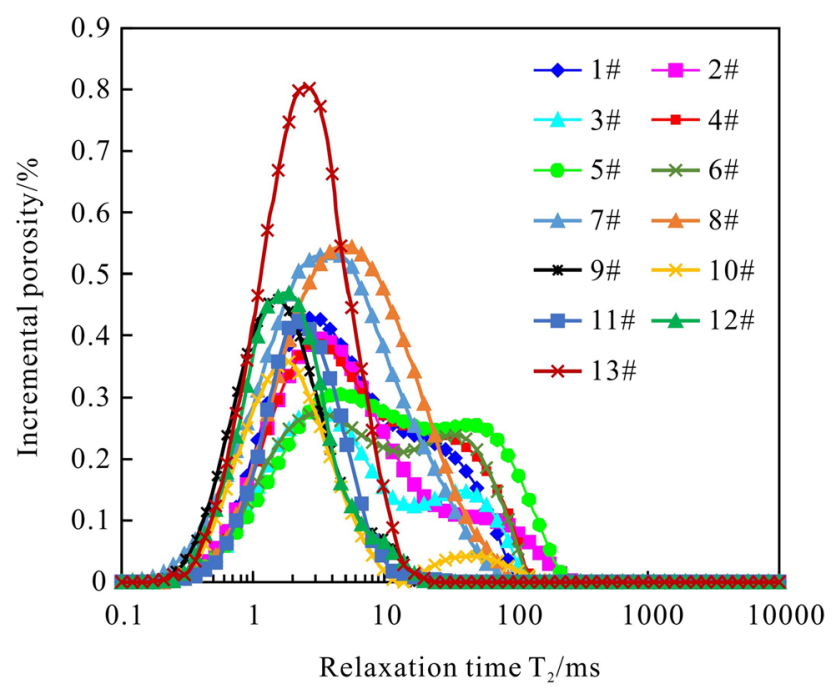

Fig. $3 T_{2}$ spectrum distribution of the samples after centrifugation
The specific method is to find a point on the abscissa of $T_{2}$ spectrum, so that the envelope area of $T_{2}$ spectrum of saturated fluid to the left side of the point is equal to the envelope area of $T_{2}$ spectrum after centrifugation, and the $T_{2}$ value of this point is $T_{2}$ cutoff value. In theory, if the flow of fluid in the pore space is only controlled by the size of pore throats, then the pore throat radius lower limit and $T_{2}$ cutoff value of movable fluid should be fixed values. Based on this limit, movable fluid and bound fluid can be distinguished. However, it can be seen from Fig. 4 that $T_{2}$ cutoff value cannot distinguish movable fluid from bound fluid in $T_{2}$ spectrum. On the other hand, it also shows that the distribution of movable fluid is not completely controlled by the size of pore throats.

\section{Distribution characteristics of movable fluid}

The percentage of the envelope area to the right of the $T_{2}$ cutoff value in the $T_{2}$ spectrum of saturation fluid to the total envelope area is the movable fluid saturation. The movable fluid saturation of 13 samples from Chang 7 reservoir in the study area ranges from 22.35 to $56.05 \%$, with an average value of $35.15 \%$. This indicates that the movable fluid saturation of tight reservoirs in the study area is generally low. Some scholars believe that movable fluid saturation can be used as a criterion for reservoir classification and reservoirs can be divided into Class I (excellent), Class II (good), Class III (medium), Class IV (poor), and Class V (very poor), the corresponding movable fluid saturation is $>65 \%, 50-65 \%$, $35-50 \%, 20-35 \%$, and $<20 \%$, respectively (Han et al. 2016; Pang et al. 2017). According to this criterion and movable fluid saturation of test samples in the study area, the results show that Chang 7 reservoir in the study area is mainly classified as Class IV, followed by Class III, the proportion of Class II is the smallest, and there are no Class I and V (Table 2).

According to the difference of $T_{2}$ spectrum amplitude before and after centrifugation, the distribution of movable fluids on $T_{2}$ spectrum can be understood. It can be seen that the distribution of movable fluids in different samples is different, but mainly distributed in the range of $T_{2}>10 \mathrm{~ms}$, that is, mainly distributed in the middle and large pores, but also a small number of movable fluids are distributed in the small pores. Therefore, finding out the factors affecting the occurrence of movable fluids and choosing suitable development forms also have certain development potential for the small pores in tight reservoirs.

The movable fluid saturation of sample $3 \#$ is $56.05 \%$, and it belongs to the Class II reservoir sample. Before centrifugation, the $T_{2}$ spectrum curve is in left-high-peak-rightlow-peak bimodal shape; after centrifugation, it is in righthigh-peak-left-low-peak bimodal shape. Before and after centrifugation, the $T_{2}$ spectrum curve changes greatly in the 

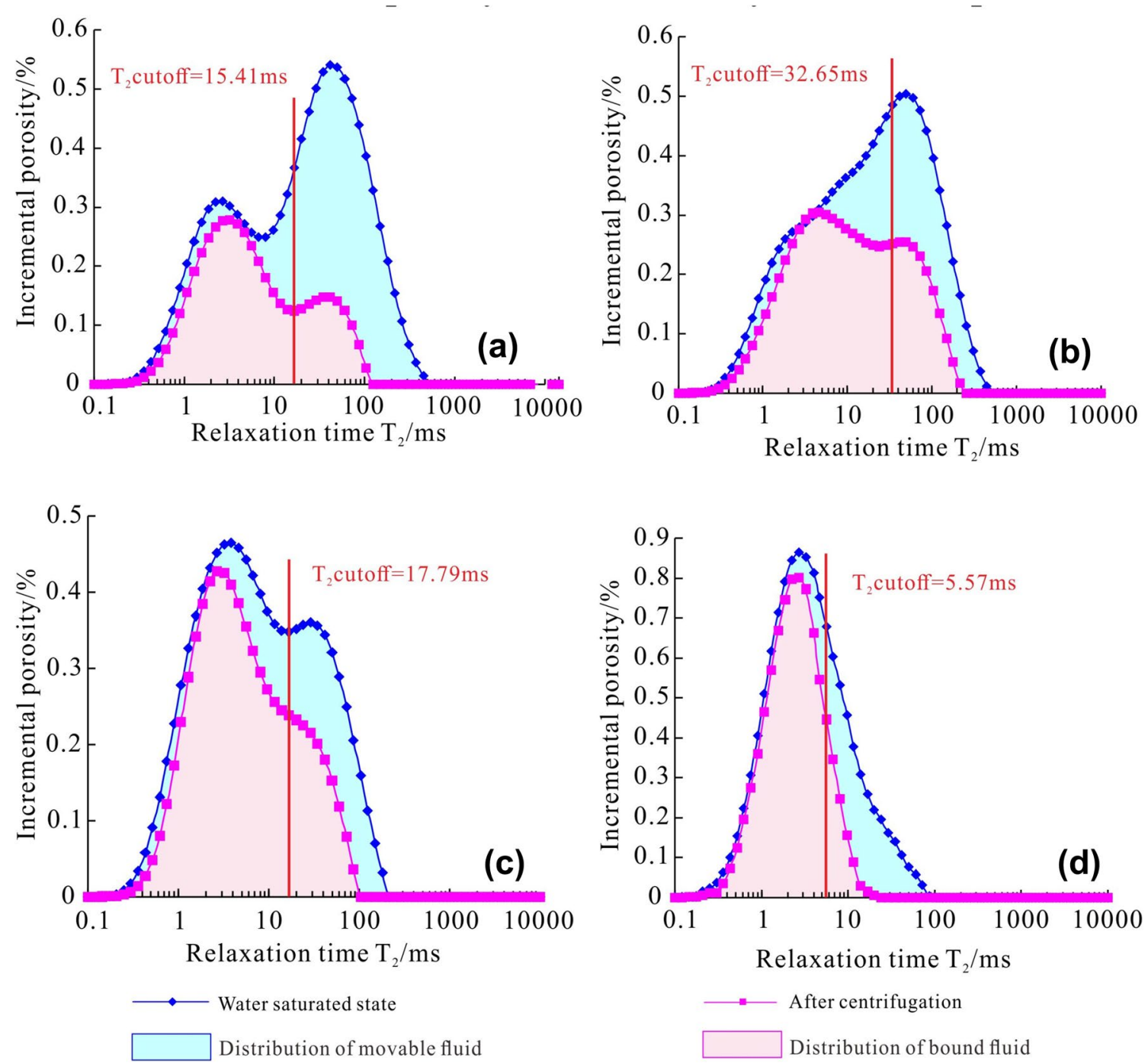

Fig. 4 Distribution characteristic of $T_{2}$ spectrum before and after centrifugation: (a) sample 3\#; (b) sample 6\#; (c) sample 7\#; (d) sample 13\#

sides of medium and large pores (Fig. 4a). It shows that there are a lot of movable fluids in medium and large pores.

Before centrifugation, the $T_{2}$ spectrum curves of Class III reservoir samples are dominated by left-high-peak-rightlow-peak bimodal shape and inconspicuous bimodal shape. A certain number of large pores are often developed in the samples with these two $T_{2}$ spectrum curves, and this part of large pores provides the space for movable fluid occurrence. For example, the movable fluid saturation of sample 6\# is $47.38 \%$, the shape of $T_{2}$ spectrum curve is inconspicuous bimodal before centrifugation and then change to left-highpeak-right-low-peak bimodal shape after centrifugation, and the shape of $T_{2}$ spectrum curve changed greatly before and after centrifugation (Fig. 4b).

Before centrifugation, the $T_{2}$ spectrum curves of Class IV reservoir samples are dominated by unimodal shape and left-high-peak-right-low-peak bimodal shape. As mentioned above, the pore throats of the samples with unimodal shape are well sorted, but the overall size is relatively small, which makes the movable fluid saturation low. For example, the movable fluid saturation of samples $7 \#$ and $13 \#$ are $28.2 \%$, $31.31 \%$, respectively. There were no significant differences, before and after centrifugation, in the shapes of $T_{2}$ spectrum curve, and in the main peak $T_{2}$ spectrum values, the movable fluid mainly exists in medium and small pores (Fig. 4c, d).

\section{Analysis of the factors influencing the occurrence characteristics of movable fluid}

The movable fluid saturation of Chang 7 tight reservoir in the study area is low as a whole, and the occurrence characteristics of movable fluids in different samples are quite different. In this paper, combined with physical analysis, pore assemblage type, pore throat structure characteristics, 
Table 2 Statistical table of NMR parameter of samples in Chang 7 reservoir before and after centrifugation

\begin{tabular}{|c|c|c|c|c|c|c|c|c|}
\hline \multirow[t]{2}{*}{ Sample ID } & \multirow{2}{*}{$\begin{array}{l}\text { Before or after } \\
\text { centrifugation }\end{array}$} & \multicolumn{3}{|c|}{$T_{2}$ spectral interval $/ \%$} & \multirow{2}{*}{$\begin{array}{l}\text { Movable } \\
\text { fluid satua- } \\
\text { tion } / \%\end{array}$} & \multirow{2}{*}{$\begin{array}{l}T_{2} \text { cutoff } \\
\text { value/ } \\
\mathrm{ms}\end{array}$} & \multirow[t]{2}{*}{ Shape of $T_{2}$ spectrum curves } & \multirow[t]{2}{*}{ Classification } \\
\hline & & $<10 \mathrm{~ms}$ & $10-100 \mathrm{~ms}$ & $\geq 100 \mathrm{~ms}$ & & & & \\
\hline \multirow[t]{2}{*}{$1 \#$} & Before & 58.59 & 37.78 & 3.63 & 30.03 & 17.79 & $\begin{array}{l}\text { Left-high-peak-right-low-peak bimodal } \\
\text { shape }\end{array}$ & IV \\
\hline & After & 69.77 & 30.23 & 0 & & & $\begin{array}{l}\text { Left-high-peak-right-low-peak bimodal } \\
\text { shape }\end{array}$ & \\
\hline \multirow[t]{2}{*}{$2 \#$} & Before & 52.14 & 38.37 & 9.49 & 34.93 & 17.85 & Inconspicuous bimodal shape & IV \\
\hline & After & 72.36 & 23.98 & 3.66 & & & $\begin{array}{l}\text { Left-high-peak-right-low-peak bimodal } \\
\text { shape }\end{array}$ & \\
\hline \multirow[t]{2}{*}{$3 \#$} & Before & 36.62 & 49.14 & 14.25 & 56.05 & 15.41 & $\begin{array}{l}\text { Right-high-peak-left-low-peak bimodal } \\
\text { shape }\end{array}$ & II \\
\hline & After & 68 & 31.44 & 0.56 & & & $\begin{array}{l}\text { Left-high-peak-right-low-peak bimodal } \\
\text { shape }\end{array}$ & \\
\hline \multirow[t]{2}{*}{ 4\# } & Before & 47.58 & 45.16 & 7.26 & 35.53 & 20.59 & Inconspicuous bimodal shape & III \\
\hline & After & 63.12 & 35.79 & 1.09 & & & $\begin{array}{l}\text { Left-high-peak-right-low-peak bimodal } \\
\text { shape }\end{array}$ & \\
\hline \multirow[t]{2}{*}{$5 \#$} & Before & 37.82 & 47.68 & 14.5 & 37.4 & 32.65 & Inconspicuous bimodal shape & III \\
\hline & After & 51.36 & 42.03 & 6.62 & & & $\begin{array}{l}\text { Left-high-peak-right-low-peak bimodal } \\
\text { shape }\end{array}$ & \\
\hline \multirow[t]{2}{*}{$6 \#$} & Before & 36.89 & 49.27 & 13.84 & 47.38 & 20.48 & Inconspicuous bimodal shape & III \\
\hline & After & 58.12 & 40.86 & 1.02 & & & $\begin{array}{l}\text { Left-high-peak-right-low-peak bimodal } \\
\text { shape }\end{array}$ & \\
\hline \multirow[t]{2}{*}{ 7\# } & Before & 63.66 & 34.95 & 1.39 & 28.2 & 13.05 & Unimodal shape & IV \\
\hline & After & 80.3 & 19.7 & 0 & & & Unimodal shape & \\
\hline \multirow[t]{2}{*}{$8 \#$} & Before & 63.08 & 35.56 & 1.36 & 22.35 & 16.29 & Unimodal shape & IV \\
\hline & After & 72.92 & 27.08 & 0 & & & Unimodal shape & \\
\hline \multirow[t]{2}{*}{ 9\# } & Before & 79.53 & 13.98 & 6.49 & 36.42 & 3.7 & $\begin{array}{l}\text { Left-high-peak-right-low-peak bimodal } \\
\text { shape }\end{array}$ & III \\
\hline & After & 98.22 & 1.78 & 0 & & & $\begin{array}{l}\text { Left-high-peak-right-low-peak bimodal } \\
\text { shape }\end{array}$ & \\
\hline \multirow[t]{2}{*}{$10 \#$} & Before & 69.66 & 18.55 & 11.78 & 34.67 & 6.6 & $\begin{array}{l}\text { Left-high-peak-right-low-peak bimodal } \\
\text { shape }\end{array}$ & IV \\
\hline & After & 91.4 & 7.74 & 0.87 & & & $\begin{array}{l}\text { Left-high-peak-right-low-peak bimodal } \\
\text { shape }\end{array}$ & \\
\hline \multirow[t]{2}{*}{$11 \#$} & After & 93.96 & 5.99 & 0.05 & 26.58 & 4.03 & Unimodal shape & IV \\
\hline & After & 98.73 & 1.27 & 0 & & & Unimodal shape & \\
\hline \multirow[t]{2}{*}{$12 \#$} & Before & 86.29 & 13.73 & 0.01 & 36.13 & 2.95 & Unimodal shape & III \\
\hline & After & 96.57 & 3.43 & 0 & & & Unimodal shape & \\
\hline \multirow[t]{2}{*}{$13 \#$} & Before & 84.27 & 15.73 & 0 & 31.31 & 5.57 & Unimodal shape & IV \\
\hline & After & 98.39 & 1.61 & 0 & & & Unimodal shape & \\
\hline
\end{tabular}

and clay mineral development status (Table 3), the factors affecting the occurrence characteristics of movable fluids in tight reservoirs are analyzed in detail.

\section{Effect of reservoir physical properties}

The average porosity and permeability of Chang 7 reservoir in the study area are $9.3 \%$ and $0.182 \times 10^{-3} \mu \mathrm{m}^{2}$, respectively. The whole reservoir is characterized by relatively high porosity and low permeability. It can be seen from Fig. 5 that the movable fluid saturation has almost no correlation with porosity. Relatively speaking, the correlation between movable fluid saturation and permeability is better. Porosity only reflects the reservoir properties, while the movable fluid saturation reflects the fluidity of the fluid in the reservoir and is related to the percolation ability of the fluid. Therefore, the correlation between the movable fluid saturation and the permeability is relatively good. However, it can also be seen that there are "high permeability and low movable saturation" and "low permeability and high movable saturation", especially in the range of permeability less than $0.1 \times 10^{-3} \mu \mathrm{m}^{2}$, which shows that the tighter the reservoir, 


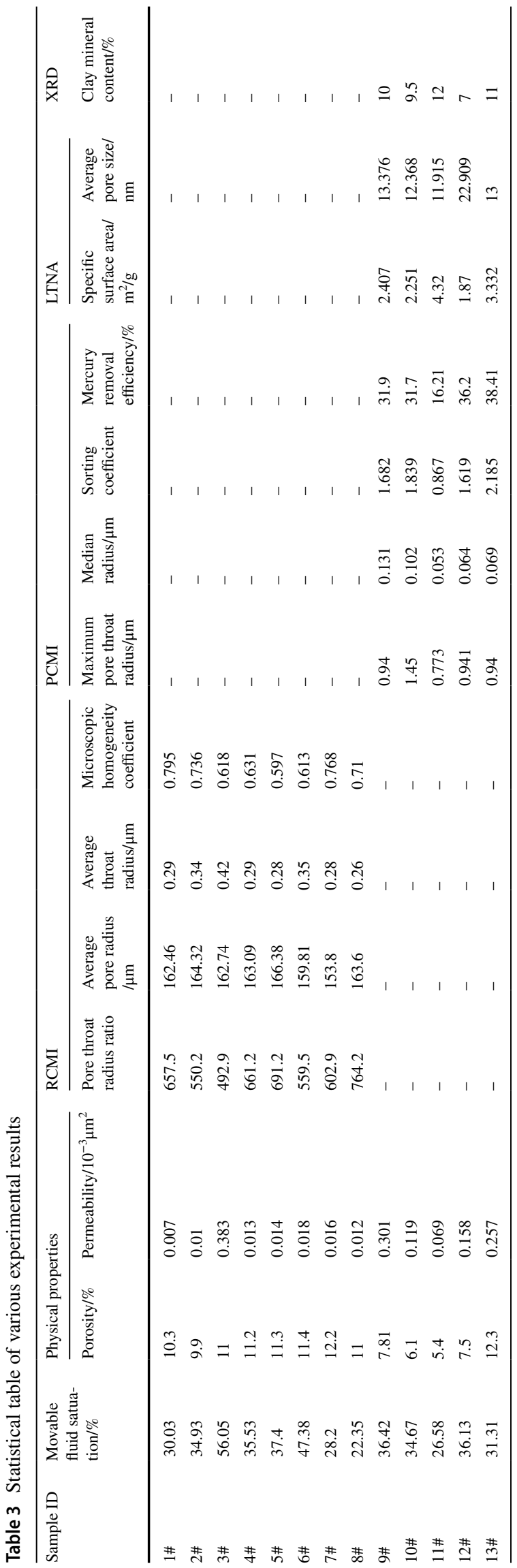

the more complex the occurrence characteristics of movable fluid, and it is often not controlled by a single factor.

\section{Effect of pore-throat structure}

According to the observation of pore development by CTS and SEM, the statistical results show that the plane porosity of Chang 7 tight sandstone reservoir in the study area is $1.89 \%$. The main developed types of pores are intergranular pore, dissolution pore (including feldspar dissolution pore, intergranular dissolution pore, lithic dissolution pore, matrix dissolution pore), intercrystalline pore, and microfissure. Previous researchers have analyzed the influence of different pore types on movable fluid saturation (Liu et al. 2016), but the fundamental reason for the difference of pore types is the size of pore throat and its configuration relationship. PCMI and RCMI are important means to study the pore throat characteristics of reservoirs, but both methods have their own advantages and disadvantages. The PCMI test has high mercury intrusion pressure, which can detect the size and structural characteristics of nano-scale pore throats. The RCMI test can effectively distinguish pores and throats and quantitatively analyze the size and distribution of pores and throats. A variety of parameters can be obtained by PCMI and RCMI, including parameters reflecting pore-throat size, pore-throat sortability, and pore-throat connectivity. This paper chooses representative parameters to analyze the influence of pore-throat structure on the occurrence characteristics of movable fluids.

\section{Size of pore throat}

The pore throat size parameters measured by PCMI include maximum pore throat radius and median radius. The maximum pore throat radius is the value of throat size which is injected first when mercury enters the pore throat network. The median radius is the pore throat radius corresponding to the mercury saturation reaches $50 \%$, which can be roughly regarded as the average pore throat radius of rocks. The average pore radius and average throat radius of each sample can be obtained by RCMI. It can be seen from Fig. 6 that the correlation between the average pore radius and the movable fluid saturation is very poor, while the parameters of throat size have a good positive correlation with the movable fluid saturation. Especially, the correlation between the average throat radius measured by RCMI and the movable fluid saturation is the best, and the correlation coefficient is 0.8199 . This shows that throat size plays a major role in controlling the flow of fluid in rocks. The size of pore determines the amount of total fluid, while the throat size determines the difficulty of fluid seepage.

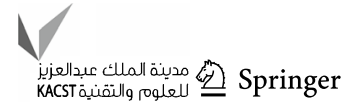



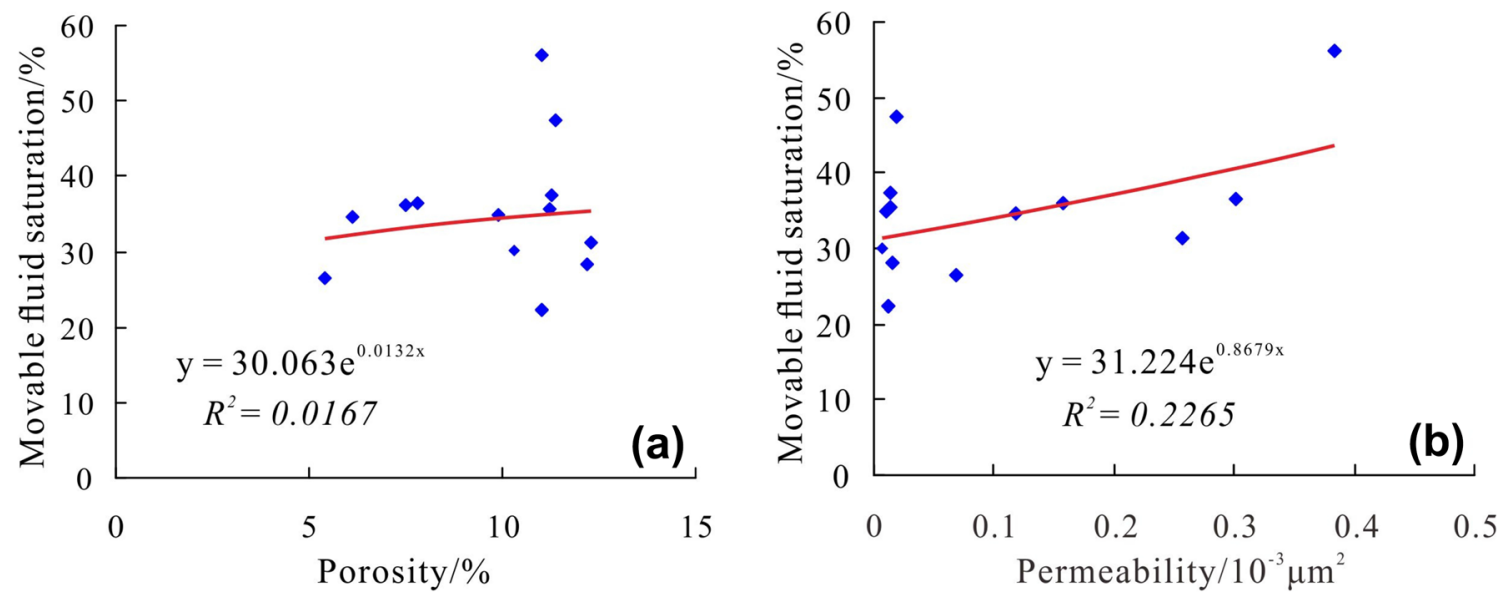

Fig. 5 Relationship between movable fluid saturation and the physical properties
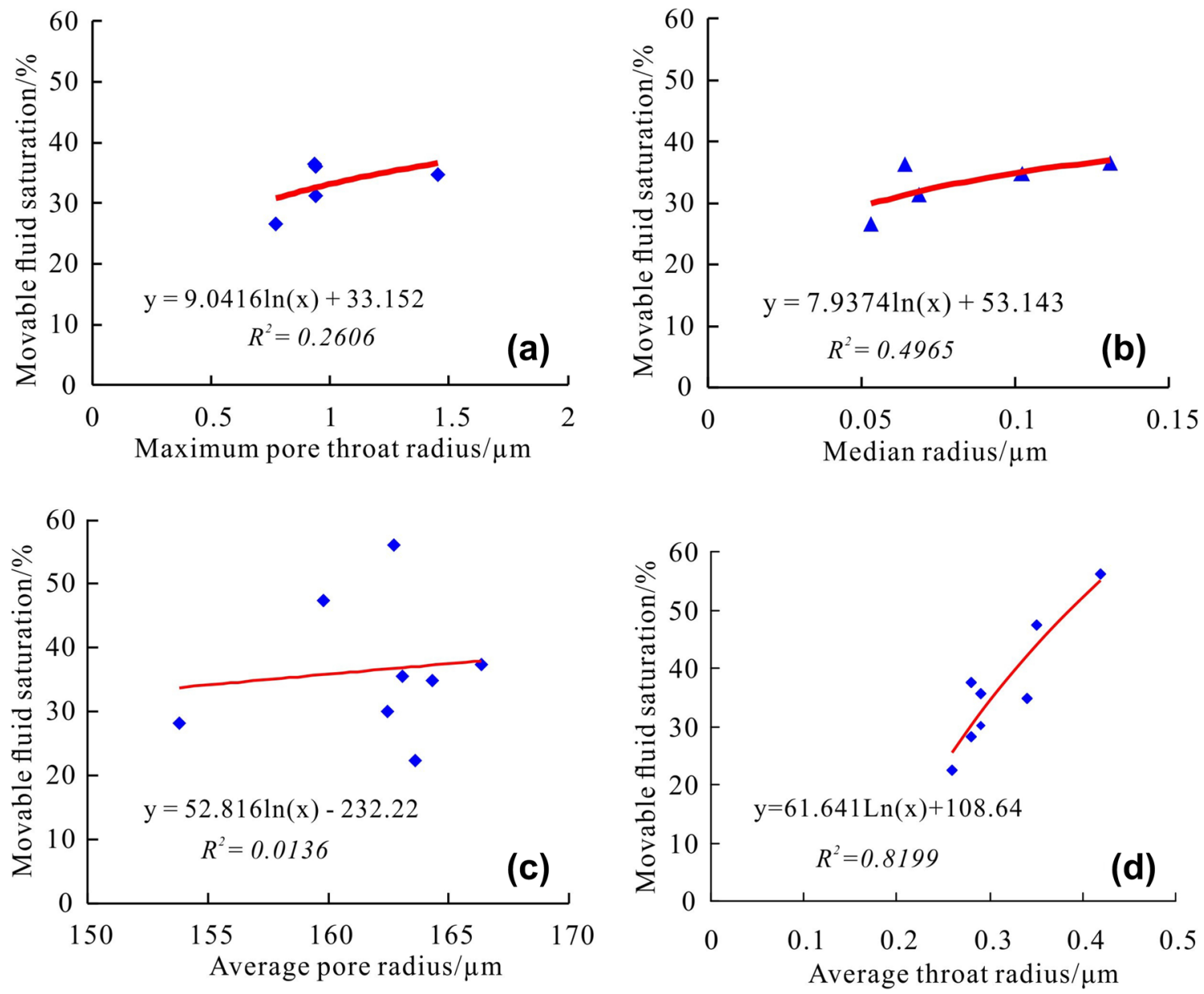

Fig. 6 Relationship between movable fluid saturation and the size of pore throat

\section{Sortability of pore throat}

The sortability coefficient in the test results of PCMI and the microscopic homogeneity coefficient in the test results of RCMI can characterize the sortability of pore throat. The smaller the value of sortability coefficient and the larger the value of microscopic homogeneity coefficient, 
the more concentrated the distribution of pore throat size and the better the sortability.

It can be seen from Fig. 7 that the movable fluid saturation is negatively correlated with the sortability of pore throat, that is, the better the sortability, the lower the movable fluid saturation. The analysis suggests that for tight reservoirs, when sortability is good, the pore throat distribution is relatively concentrated, but the overall size is small, which makes a large number of fluids are bounded and difficult to flow; when the sorting performance is poor, the pore throat size distribution is different, relatively the large pore throat is more developed, and the existence of the large pore throat provides the storage space for movable fluids. Therefore, the size of pore throat is the main factor affecting the occurrence of movable fluids.

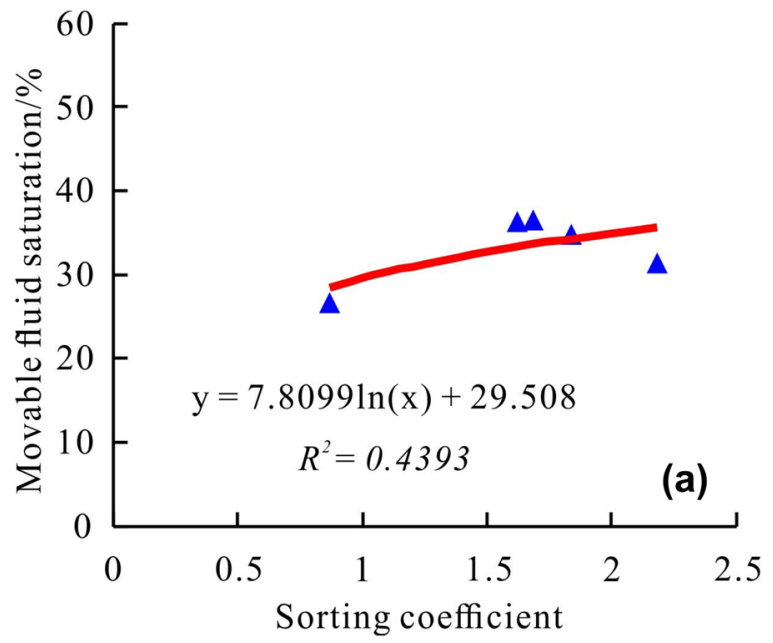

\section{Connectivity of pore throat}

The mercury removal efficiency measured by PCMI can not only reflect the quality of the pore throat configuration in the reservoir, but also, to a certain extent, characterize the recovery efficiency of non-wetting phase and the pore throat connectivity. The pore-to-throat ratio measured by RCMI refers to the ratio of pore radius to throat radius, reflecting the configuration relationship between pores and throats. The larger the pore-to-throat ratio, the larger the pores and the relatively smaller the throats, the more difficult the fluid to flow. Otherwise, the seepage capacity is better. From Fig. 8, it can be seen that the movable fluid saturation is positively correlated with the mercury removal efficiency and negatively correlated with the pore-to-throat radius ratio. Poor connectivity of pore-throat often leads to fluid

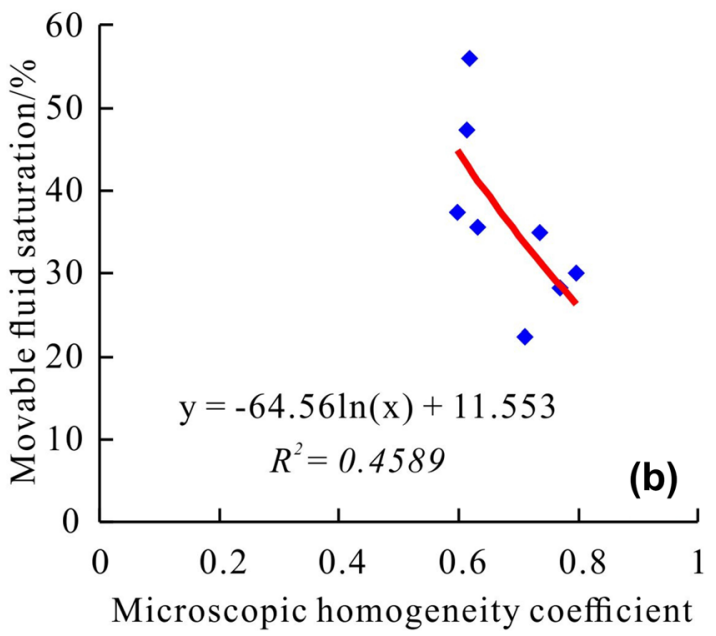

Fig. 7 Relationship between movable fluid saturation and the sortability of pore throat
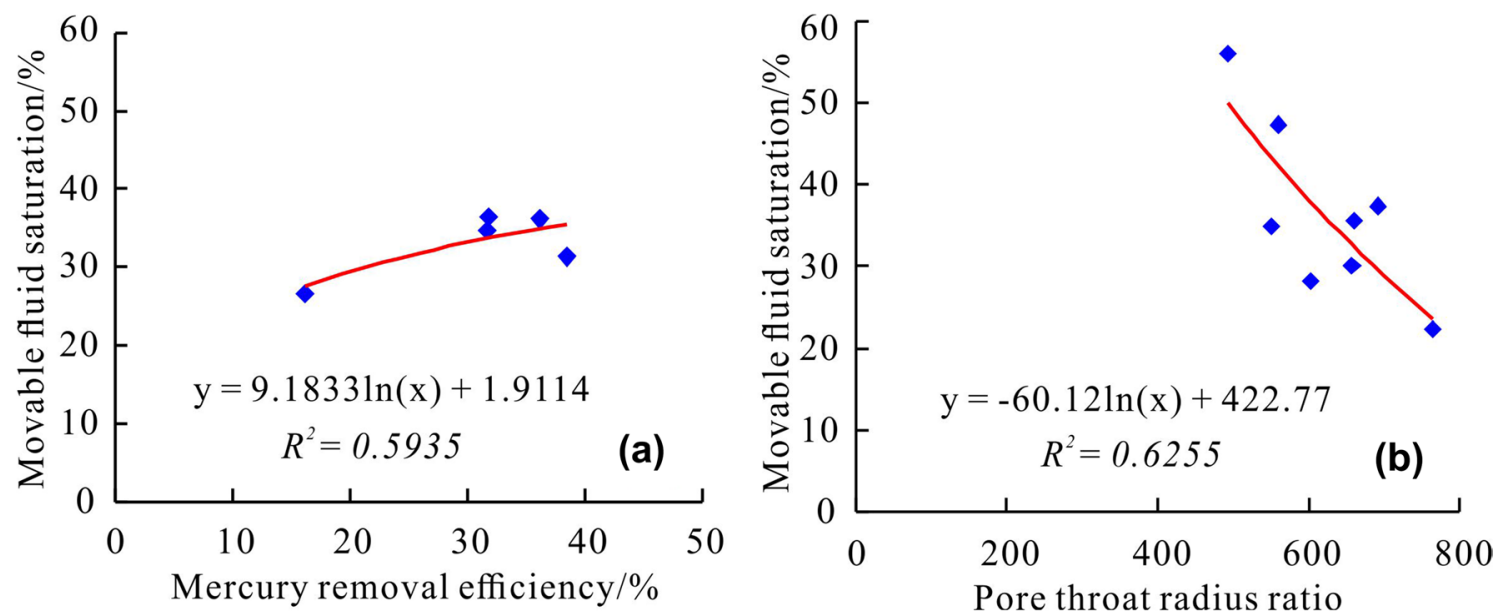

Fig. 8 Relationship between movable fluid saturation and the connectivity of pore throat 
seepage difficulty, and fluid is bounded in the pores and difficult to flow, resulting in low saturation of movable fluids.

From the above analysis, it can be seen that the size and connectivity of pore throat in pore-throat structural parameters are the main factors affecting the movable fluid saturation in tight reservoirs. Although a large number of micronano-scale pore throats developed in tight reservoirs provide space for fluid occurrence, due to small throat radius and poor connectivity between pores and throats, it is difficult for a large number of fluids to flow in the tiny pore throat.

\section{Effect of clay minerals}

X-ray diffraction analysis shows that the absolute content of clay minerals in Chang 7 reservoir is $9.83 \%$. The clay minerals are mainly illite (5.87\%), followed by chlorite (2.44\%), illite/smectite mixed layers (0.98\%), and kaolinite $(0.54 \%)$. Illite has fibrous structure and distributes in pores and/or on the surface of clastic grains (Fig. 9a). Chlorite is needle-shaped or rose-shaped and it is coating on the surface of sandstone grains (Fig. 9b). Illite/smectite mixed layers are the transition minerals from smectite to illite, mostly in the form of honeycomb (Fig. 9c). Kaolinite has booklet structure and it is mostly in the form of pore filling in the pores (Fig. 9d).

LTNA experiment can measure the specific surface area, pore size, and distribution of the nano-scale pores. Five samples of Chang 7 reservoir in the study area were tested for LTNA, and the average pore size and specific surface area were obtained. Through correlation analysis, it can be seen that average pore size and movable fluid saturation are negatively correlated with clay mineral content, and specific surface area is positively correlated with clay mineral content (Fig. 10). This shows that intracrystalline pore of clay minerals is the main contributor to nano-scale pores of tight reservoirs. The higher the clay mineral content, the smaller the average pore size and the larger the specific surface area.
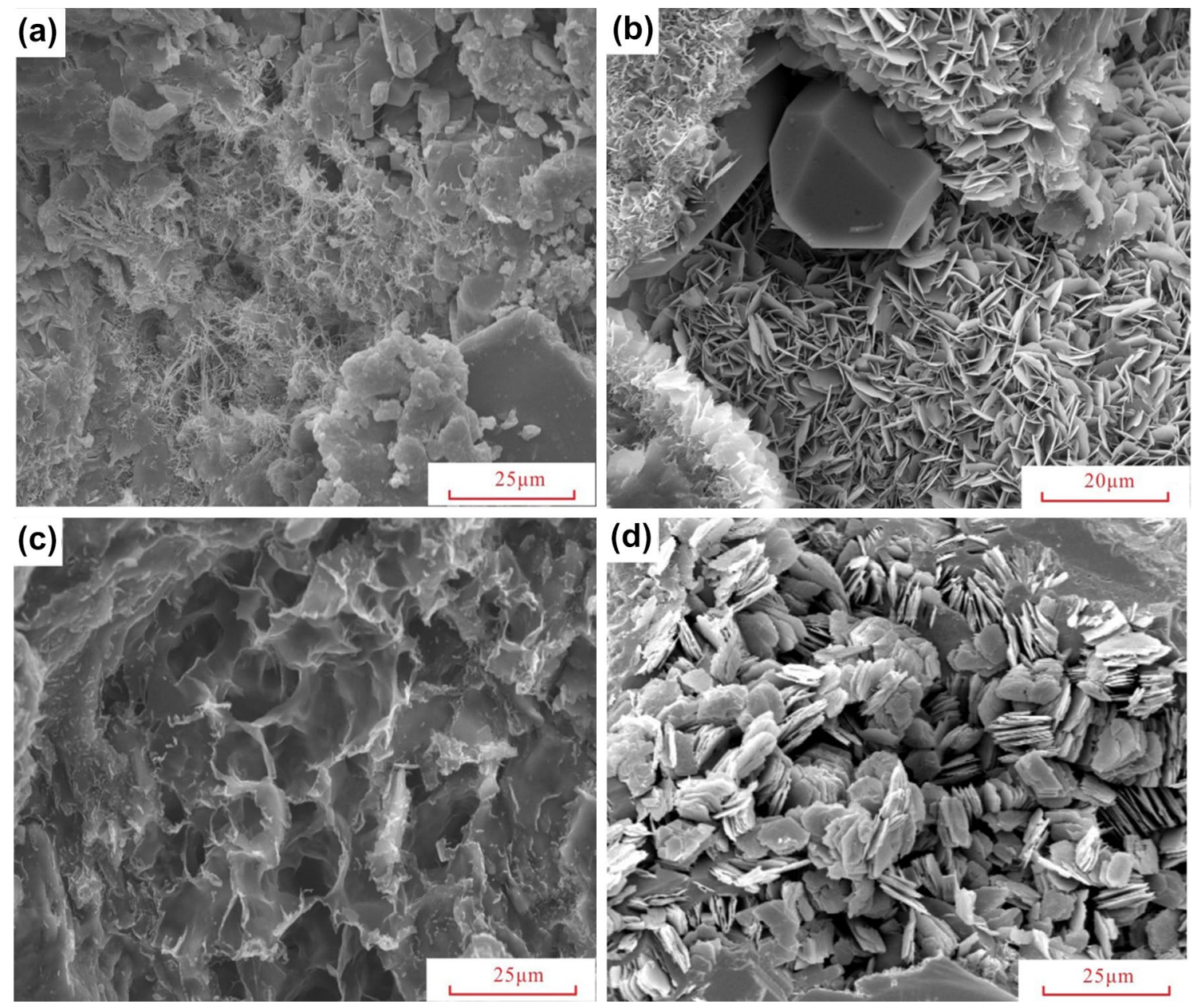

Fig. 9 Clay mineral photos of Chang7 tight sandstone reservoir in study area: (a) illite with fibrous structure; (b) chlorite with needle-shaped or rose-shaped; (c) illite/smectite mixed layer with honeycomb structure; (d) kaolinite with booklet structure in the pores

$\sqrt{ }$

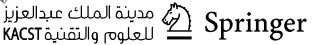



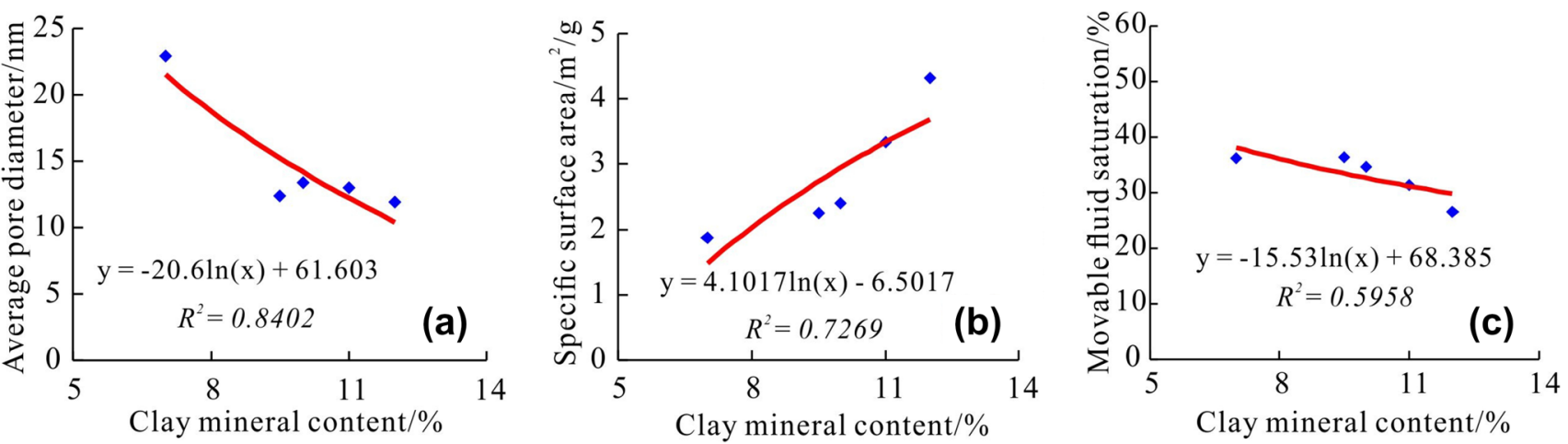

Fig. 10 Relationship between clay mineral content and (a) average pore size; (b) specific surface area; (c) movable fluid saturation

The analysis shows that the influence of the development of clay minerals on the occurrence characteristics of movable fluids is mainly manifested in two aspects: (1) The existence of various clay minerals will make the pore throats smaller and more complex, especially the development of illite and illite/smectite mixed layers will divide a pore into several micropores, reduce the average pore size, make the pore connectivity worse, and increases the fluid seepage resistance. (2) The development of clay minerals enlarges the specific surface area, which means that the contact surface between rocks and pore fluids increases, so that a large number of fluids are adsorbed on the clay surface and difficult to flow, resulting in reduced movable fluid saturation. In addition, some scholars believe that the removal and migration of clay minerals will block the throats and reduce the movable fluid saturation ( $\mathrm{Li}$ et al. 2018a, b, c). Some scholars believe that the hydrophilicity of clay minerals will increase the thickness of water film, make the throats narrow or plug the throats and reduce the movable fluid saturation.

\section{Conclusions}

1. The $T_{2}$ spectrum curves of saturated fluid samples from Chang 7 tight sandstone reservoir in the study area can be divided into four types of $T_{2}$ spectrum shapes: lefthigh-peak-right-low-peak bimodal shape, right-highpeak-left-low-peak bimodal shape, unimodal shape, and inconspicuous bimodal shape. The overall shapes are mainly unimodal shape and inconspicuous bimodal shape. After centrifugation, the shape of $T_{2}$ spectrum curve is dominated by left-high-peak-right-low-peak bimodal shape, indicating that the bound fluid is mainly distributed in the small pores.

2. The average movable fluid saturation in Chang 7 tight reservoir is $33.27 \%$, and the average $T_{2}$ cutoff value is $13.61 \mathrm{~ms}$. Movable fluids are mainly distributed in medium and large pores, and a small amount in small pores.

3. The movable fluid saturation is positively correlated with porosity and permeability, and the correlation with permeability is better. The tighter the reservoir, the more complex the occurrence characteristics of movable fluids, which is not controlled by a single factor. The size of throats and the connectivity of pore-throat have an obvious influence on the movable fluid saturation. The small size of throats and the poor connectivity of pore-throat in tight reservoirs not only restrict the fluid flowing in micropores, but also make the fluid in macropores difficult to flow under the control of small throats.

4. The development of clay minerals will make the pore throat smaller, more complex and have poorer connectivity, and increase the seepage resistance of fluids. On the other hand, it will make the specific surface area larger, causing a large number of fluids to be adsorbed on the clay surface and difficult to flow and reduce the movable fluid saturation.

Funding National Natural Science Foundation of China: Diagenetic response of high thermal and overpressure background and the influence of fluid activity on Diagenetic pore evolution of reservoir (41972129).

Open Access This article is licensed under a Creative Commons Attribution 4.0 International License, which permits use, sharing, adaptation, distribution and reproduction in any medium or format, as long as you give appropriate credit to the original author(s) and the source, provide a link to the Creative Commons licence, and indicate if changes were made. The images or other third party material in this article are included in the article's Creative Commons licence, unless indicated otherwise in a credit line to the material. If material is not included in the article's Creative Commons licence and your intended use is not permitted by statutory regulation or exceeds the permitted use, you will need to obtain permission directly from the copyright holder. To view a copy of this licence, visit http://creativecommons.org/licenses/by/4.0/.

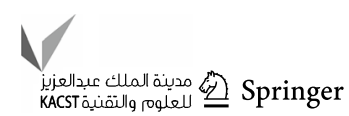




\section{References}

Al-Mahrooqi SH, Grattoni CA, Moss AK et al (2003) An investigation of the effect of wettability on NMR characteristics of sandstone rock and fluid systems. J Petrol Sci Eng 39(3):389-398

Al-Mahrooqi SH, Grattoni CA, Muggeridge AH et al (2006) Pore-scale modelling of NMR relaxation for the characterization of wettability. J Petrol Sci Eng 52(1-4):172-186

Bai B, Zhu R, Wu S, Cui J et al (2014) New micro-throat structural characterization techniques for unconventional tight hydrocarbon reservoir. China Petrol Explor 19(3):78-86

Baouche R, Aïfa T, Baddari K (2017) Intelligent methods for predicting nuclear magnetic resonance of porosity and permeability by conventional well-logs: a case study of Saharan field. Arab J Geosci 10(24):545

Chen J, Hirasaki GJ, Flaum M (2006) NMR wettability indices: effect of OBM on wettability and NMR responses. J Petrol Sci Eng 52(1-4):161-171

Chen M, Dai J, Liu X et al (2019) Contributions of pore-throat size distribution to reservoir quality and fluid distribution from NMR and MIP in tight sandy conglomerate reservoirs. Arab J Geosci 12(1):1-12

Daigle H, Johnson A (2015) Combining mercury intrusion and nuclear magnetic resonance measurements using percolation theory. Transp Porous Media 111(3):1-11

Fang T, Zhang L, Liu N et al (2017) Quantitative characterization of pore structure of tight gas sandstone reservoirs by NMR $T_{2}$ spectrum technology: a case study of Carboniferous-Permian tight sandstone reservoir in Linqing depression. Acta Petrol Sin 38(8):902-915

Gao H, Liu Y, Zhang Z et al (2015) Impact of secondary and tertiary floods on microscopic residual oil distribution in medium-tohigh permeability cores with NMR technique. Energy Fuels 29(8):4721-4729

Guana H, Broughamb D, Sorbiea KS et al (2002) Wettability effects in a sandstone reservoir and outcrop cores from NMR relaxation time distributions. J Petrol Sci Eng 34(1-4):35-54

Guo R, Chen X, Ma X et al (2018) Analysis of the characteristics and its influencing factors of horizontal movable fluid in the Chang7 tight reservoir in Longdong area. Ordos Basin Nat Gas Geosci 29(5):665-674

Han W, Tao S, Yao J et al (2016) Tight sandstone reservoirs characterization od Chang 7 member in Longdong area. Ordos Basin Nat Gas Geosci 27(5):820-826

Jin G, Xie R, Xiao L (2020) Nuclear magnetic resonance characterization of petrophysical properties in tight sandstone reservoirs. J Geophys Res Sol Earth. https://doi.org/10.1029/2019JB018716

Jin G, Xie R, Xiao L et al (2021) Quantitative characterization of bound and movable fluid microdistribution in porous rocks using nuclear magnetic resonance. J Petrol Sci Eng 196:107677

Kenyon WE (1992) Nuclear magnetic resonance as a petrophysical measurement. Nucl Geophys 6(2):153-171

Lai J, Wang G, Fan Z et al (2016) Insight into the pore structure of tight sandstones using NMR and HPMI measurements. Energy Fuels 30(12):10200-10214

Lai J, Wang G, Fan Z et al (2018a) Fractal analysis of tight shaly sandstones using nuclear magnetic resonance measurements. AAPG Bull 102(2): 175-193

Lai J, Wang G, Wang Z et al (2018b) A review on pore structure characterization in tight sandstones. Earth Sci Rev 177:436-457

Lala AMS, El-Sayed EM (2015) Calculating absolute permeability using nuclear magnetic resonance models. Arab J Geosci 8(10):7955-7960

Li C, Zhou C, Li X et al (2010) A novel model for assessing the pore structure of tight sands and its application. Appl Geophys 7(3):283-291
Li H, Guo H, Liu Q et al (2014) NMR experimental study of water displacing oil of tight oil reservoir. J Cent South Univ (Sci Technol) 45(12):4370-4376

Li H, Zhang Z, Shi Y (2016) New characterization on the petrophysical characteristics of tight sandstone reservoirs in Yanchang Formation Ordos Basin China. Energy Explor Exploit 34(6):844-864

Li M, Wang H, Chen M (2018a) Distribution characteristic and influencing factors of movable fluid in tight sandstone reservoirs: a case study of Lucaogou Formation in Jimsar Sag. NM China Lithol Reserv 30(1):140-149

Li P, Sun W, Wu B et al (2018b) Occurrence characteristics and main controlling factors of movable fluids in Chang $8_{1}$ reservoir, Maling Oilfield, Ordos Basin, China. J Pet Explor Prod Technol 9(1):17-29

Li P, Sun W, Yan J et al (2018c) Characteristics of movable fluids and controlling factors in different flow units of Chang $8_{1}$ reservoir in Maling oil field. Ordos Basin Petrol Geol Exp 40(3):362-371

Liang X, Mao Z, Jin Y (2015) Tight gas sandstone reservoirs evaluation from nuclear magnetic resonance (NMR) logs: case studies. Arab J Sci Eng 40(4):1223-1237

Liu W, Xiao Z, Yang S et al (2009) Comparative studies on methods of evaluation of reservoir pore structure by using NMR(nuclear magnetic resonance) well logging data. Oil Geophys Prospect 44(6):773-778

Liu D, Sun W, Ren D et al (2016) Features of pore-throat structures and movable fluid in tight gas reservoir: a case from the 8th member of Permian Xiashihezi Formation and the 1st member of Permian Shanxi Formation in the western area of Sulige Gasfield. Ordos Basin Nat Gas Geosci 27(12):2136-2146

Liu Y, Zhang Y, Wang Y et al (2018) The pore structure of tight limestone-Jurassic Ziliujing Formation, Central Sichuan Basin. China Appl Geophys 15(2):165-174

Pang Z, Li Y, Zhao X et al (2017) Study on movable fluid saturation in ultra low permeability reservoir: taking Chang6 reservoir in Ganguyi oil field as an example. Prog Geophys 32(2):702-708

Pape H, Arnold J, Pechnig R et al (2009) Permeability prediction for low porosity rocks by mobile NMR. Pure Appl Geophys 166(5-7):1125-1163

Ren D, Sun W, Lu T et al (2015) Microscopic geological factors of movable fluid distribution in the tight sandstone gas reservoir: taking the He 8 reservoir in the east of Sulige gas field as an example. Geoscience 29(6): 1409-1417

Shi J, Qu X, Lei Q et al (2016) Distribution characteristics and controlling factors of movable fluid in tight oil reservoir: a case study of Chang 7 reservoir in Ordos Basin. Nat Gas Geosci 27(5):827-834

Wang W, Guo H, Ye C (2001) The evaluation of development potential in low permeability oil field by the aid of NMR movable fluid detecting technology. Acta Petrol Sin 22(6):40-44

Wang W, Zhao G, Gu C et al (2005) Experiment and application of NMR technology on cuttings. Pet Explor Dev 32(1):56-59

Xiao L (2008) Application of NMR log data to formation pore structure evaluation. Xinjiang Petrol Geol 29(2):260-263

Xiao L, Liu X, Zou C et al (2014) Comparative study of models for predicting permeability from nuclear magnetic resonance (NMR) logs in two chinese tight sandstone reservoirs s. Acta Geophys 62(1):116-141

Xiao P, Leng X, Xiao H et al (2017) Investigation effect of wettability and heterogeneity in water flooding and on microscopic residual oil distribution in tight sandstone cores with NMR technique. Open Phys 15(1):544-550

Yang Z, Jiang H, Zhu G et al (2008) Research on reservoir evaluation index for low-premeability water-bearing gas reservoir. Acta Petrol Sin 29(2):252-255

Yang H, Dou W, Liu X et al (2010) Analysis on sedimentary facies of member7 in Yanchang Formation of Triassic Yanchang Formation. Ordos Basin Acta Sedimentol Sin 28(8):254-263 
Yang P, Guo H, Yang D (2013) Determination of residual oil distribution during waterflooding in tight oil formations with NMR relaxometry measurements. Energy Fuels 27(10):5750-5756

Yang Z, Fu J, Guo Q et al (2017) Discovery, characteristics and resource potential of continental tight oil in Triassic Yanchang Formation. Ordos Basin China Petrol Explor 22(6):9-15

Yao J, Deng X, Zhao Y et al (2013) Characteristics of tight oil in Triassic Yanchang Formation. Ordos Basin Petrol Explor Dev 40(2):150-158

Zhang G, Huang C, Hirasaki GJ (2000) Interpretation of wettability in sandstones with NMR analysis. Log Anal 41(3):223-233

Zou C, Zhu R, Bai B et al (2011) First discovery of nano-pore throat in oil and gas reservoir in China and its scientific value. Acta Petrol Sin 27(6): 1857-1864
Zou C, Yang Z, Zhang G et al (2014) Conventional and unconventional petroleum "orderly accumulation": concept and practical significance. Pet Explor Dev 41(1):14-27

Publisher's Note Springer Nature remains neutral with regard to jurisdictional claims in published maps and institutional affiliations. 